\title{
PROTECTIVE EFFECT OF Solanum indicum LEAF EXTRACT AGAINST Pb2+- INDUCED LIPID PEROXIDATION AND HEPATOMEGALY IN ALBINO RATS
}

\author{
${ }^{1}$ TUGBOBO, O.S., ${ }^{2}$ AJAO, I.O. AND ${ }^{1}$ IDOWU, K.S \\ ${ }^{1}$ Department of Science Technology, Biochemistry Unit, Federal Polytechnic, Ado-Ekiti \\ ${ }^{2}$ Department of Mathematics and Statistics, Federal Polytechnic, Ado-Ekiti, Nigeria.
}

DOI: $10.31364 /$ SCIRJ/v7.i4.2019.P0419631

http://dx.doi.org/10.31364/SCIRJ/v7.i4.2019.P0419631

\begin{abstract}
Indiscriminate bioaccumulation of heavy metals in body have been linked to oxidative stress arising from peroxidation of membrane of biomolecules which consequently manifest as neurologic, hepatic, renal and cardiovascular disorders. Therefore this study is sought to investigate the protective and inhibitory effect of Solanum indicum leaf extract against lead acetate induced lipid peroxidation and hepatomegaly in liver of albino rats. Results showed that incubation of liver homogenate with the pro-oxidant $\left(\mathrm{Pb}^{2+}\right)$ caused significant $(\mathrm{P}<0.05)$ increase in levels of thiobarbituric reactive substances (TBARS), while the extract offered highly significant $(\mathrm{P}<0.05)$ dose dependent inhibitory potential against the increase in TBARS induced by the pro-oxidant. Besides, results showed that treatment of rats in vivo with the respective doses of the extract significantly altered and attenuated serum and liver levels of biomarker enzymes (AST, ALT and ALP) in group C animals compared to rats in group B fed with lead acetate only that demonstrated significant $(\mathrm{P}<0.05)$ increase in enzyme activity while control group A received no treatment. Hence, the results suggest that Solanum indicum extract could confer protection on the liver tissues against oxidative stress and hepatomegaly and the extract may not be toxic at the doses investigated.
\end{abstract}

Keywords: Lead acetate, hepatomegaly, lipid peroxidation, Solanum indicum, thiobarbituric acid reactive substances

\section{INTRODUCTION}

High levels of lead in the body have been linked to oxidative stress arising from peroxidation of membrane of internalized tissues and macromolecules. This usually results or manifests as neurologic, renal, hepatic as well as cardiovascular disorders (Minotti and Aust, 1987). Hepatic disorders are on the increase worldwide necessitating the continued search for bioactive agent with hepatoprotective property. Measurement of thiobarbituric acid reactive substances (TBARS) in tissues is widely used as an index of lipid peroxidation (Belle et al., 2004). Besides, several in vitro and in vivo studies reported that phenolics and flavonoids rich extracts protect against oxidative stress due to their high radical scavenging potentials (Roja and Rao, 2000). This also has attracted increase attention in which the present study sought to investigate the protective potential of Solanum indicum leaf extract against lead-induced hepatotoxicity and its effects on biomarker enzymes.

\section{MATERIALS AND METHODS}

\section{Plant Extract}

The Solanum indicum leaves were collected and air dried for two months at room temperature. The air dried pulps were ground to fine powder. $500 \mathrm{~g}$ sample of the fine powder was soaked in $2000 \mathrm{ml}$ of distilled water for $72 \mathrm{hrs}$, filtered and freeze dried to obtain the extract and was kept in freezer at $4^{0} \mathrm{C}$ for further studies.

\section{Chemicals and Reagents}


Lead acetate [ $\left(\mathrm{CH}_{3} \mathrm{COO}\right)_{2} \mathrm{~Pb} .3 \mathrm{H}_{2} 0$ mol. wt. 379.33, 99.999\%, CAS No. 6080-56-4; Aldrich Chemical Co. Inc. (U.S.A)] were dissolved in distilled water and 2-3 drops of acetic acid was used to dissolve the lead acetate precipitate. They were administered at a dose of $2.5 \mathrm{mg} / \mathrm{kg}$ body weight corresponding to $1 / 10 \mathrm{th}$ of approximate environmental human daily exposure level (Preston, et al, 1987; Escribano, et al, 1997). All other reagents and chemicals were of analytical grade and were obtained from Sigma Chemical Co.St. Lous, MO, USA.

\section{Experimental Design}

The in vivo and in vitro experiments conducted involved biomarker enzymes assay and TBARS assay respectively. Twelve albino rats weighing between 150-200g were used for this study. The animals were randomly distributed into cages and allowed to acclimatized for 2 week in a well ventilated room at room temperature $\left(28^{\circ} \mathrm{C} \pm 2^{\circ} \mathrm{C}\right)$ under natural lighting condition and were fed standard rat chow and clean water ad libitum.

\section{Experimental Protocol}

The rats were divided into three groups A, B and C. Group A served as control and fed with distilled water only, animals in group B received lead acetate only while group C animals were simultaneously fed $2.5 \mathrm{mg} / \mathrm{kg}$ lead acetate as $1 / 10^{\text {th }}$ of the lethal dose concentration of the pro-oxidant and $150 \mathrm{mg} / \mathrm{kg}$ Solanum indicum leaf extract determined by method of (Lorke,1983). Solanum indicum extract was administered orally using a calibrated $1 \mathrm{~mL}$ syringe with attached polythene cannula. The animals were then sacrificed and blood samples quickly collected into EDTA sterile bottles. These were further used for biochemical assay of aspartate amino transferase (AST), alanine amino transferase (ALT) and alkaline phosphatase (ALP) by methods described by (Reitman and Frankel, 1957), and (Englehardt et al, 1970) respectively.

\section{RESULTS AND DISCUSSION}

Figure 1 and 2 show the in vivo biomarker enzymes activities in the heart and liver of the test rats. The results obtained in Figure 1 indicate that group B animals fed with lead acetate demonstrated higher enzyme activitydue to lead toxicity which was restored in group C animals when compared with the control. Serum ALT exhibited highest enzyme activity at (27.58U/L) in the heart of the test rats while serum ALP had the lowest level at (10.95U/L) thus, depicting degree of lead toxicity in the animals. However, this level of lead toxicity was reduced in group C animals fed simultaneously with the leaf extract of Solanum indicum where the least enzyme activity at $(7.58 \mathrm{U} / \mathrm{L})$ was obtained in serum ALP as shown in Figure 1.This study revealed that the serum had the highest level of enzyme activity despite being prevalent in the liver, this could result from tissue damage or assault to the plasma membrane of liver due to concentration of lead ions which further results in de novo synthesis of enzyme molecules (Yakubu et al., 2001) 


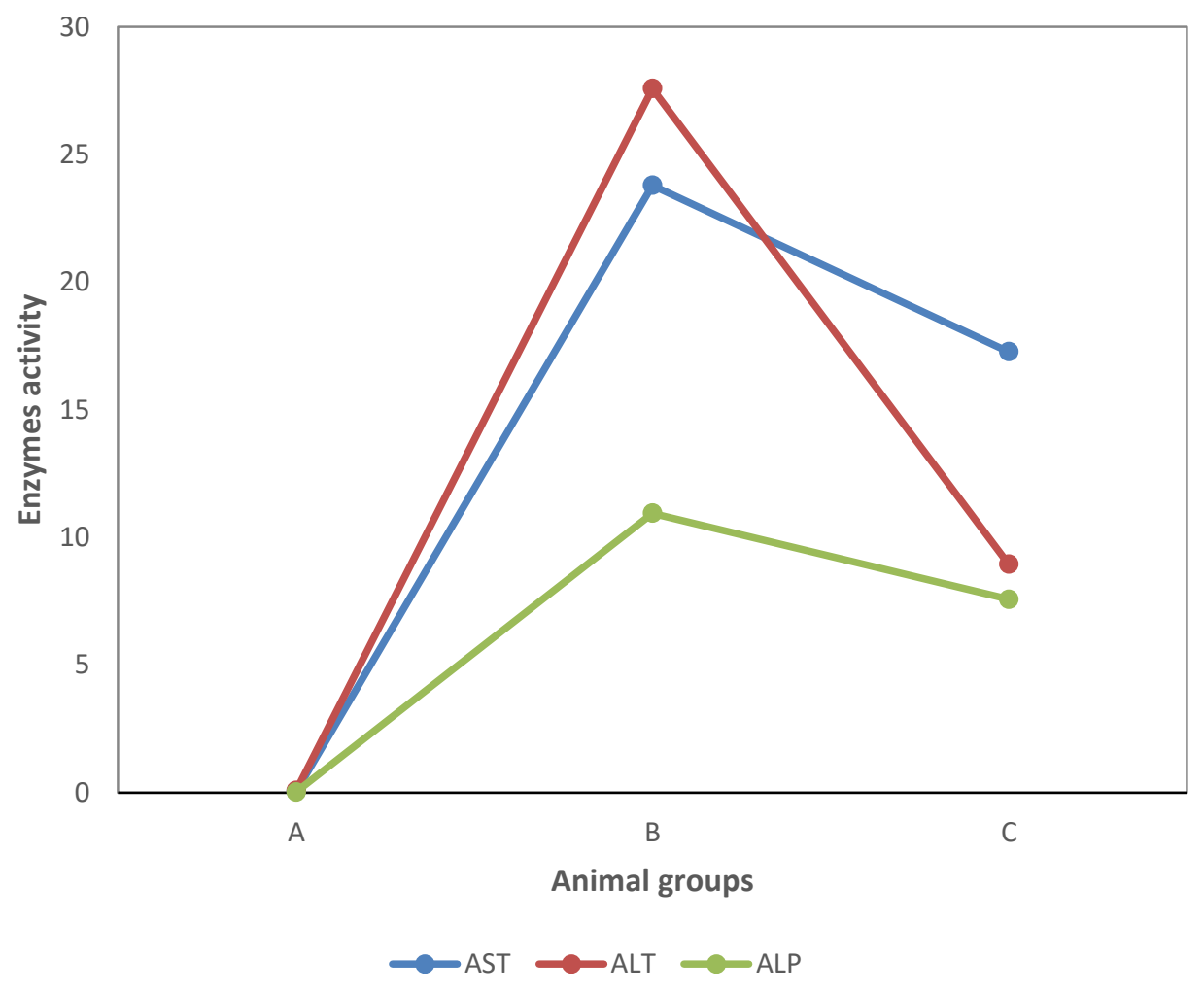

Figure 1: Enzymes activities in serum of rats fed lead acetate and Solnum indicum leaf extract

Similarly in group B animals, biomarker enzymes activities were significantly $(\mathrm{P}<0.05)$ high in liver ALP, ALT and AST respectively (Figure 2) which was gradually reduced and restored in group C. This reduced enzyme activity in group C animals could be attributed to hepatoprotective effect and inherent antioxidant properties of Solanum indicum leaf extract. 


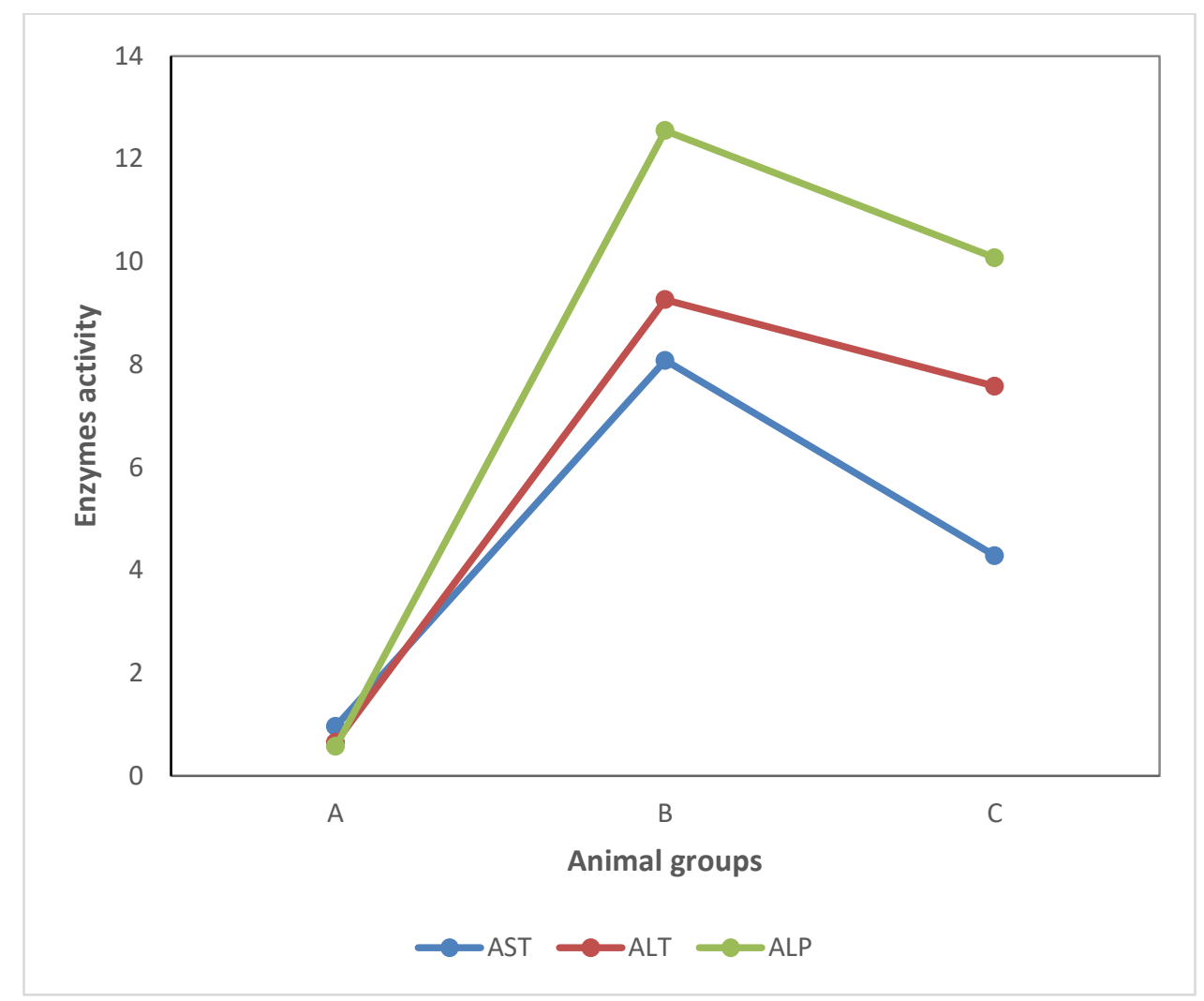

Figure 2: Enzymes activities liver of rats fed lead acetate and Solnum indicum leaf extract

In addition, the results from lipid peroxidation assay showed remarkable increase in levels of thiobarbituric reactive species (TBARS) on administration of lead acetate in group B. The findings that $\mathrm{Fe}^{2+}$ caused a significant increase in MDA content in the brain (Oboh et al., 2007) agreed with this study where the elevated levels of thiobarbituric reactive species induced by $\mathrm{Pb}^{2+}$ in rat liver was sharply decreased with the administration of Solanum indicum leaf extract. Figure 3 below shows that aqueous extract exhibited higher inhibitory potential against lead acetate induced lipid peroxidation in rat liver in vitro. 


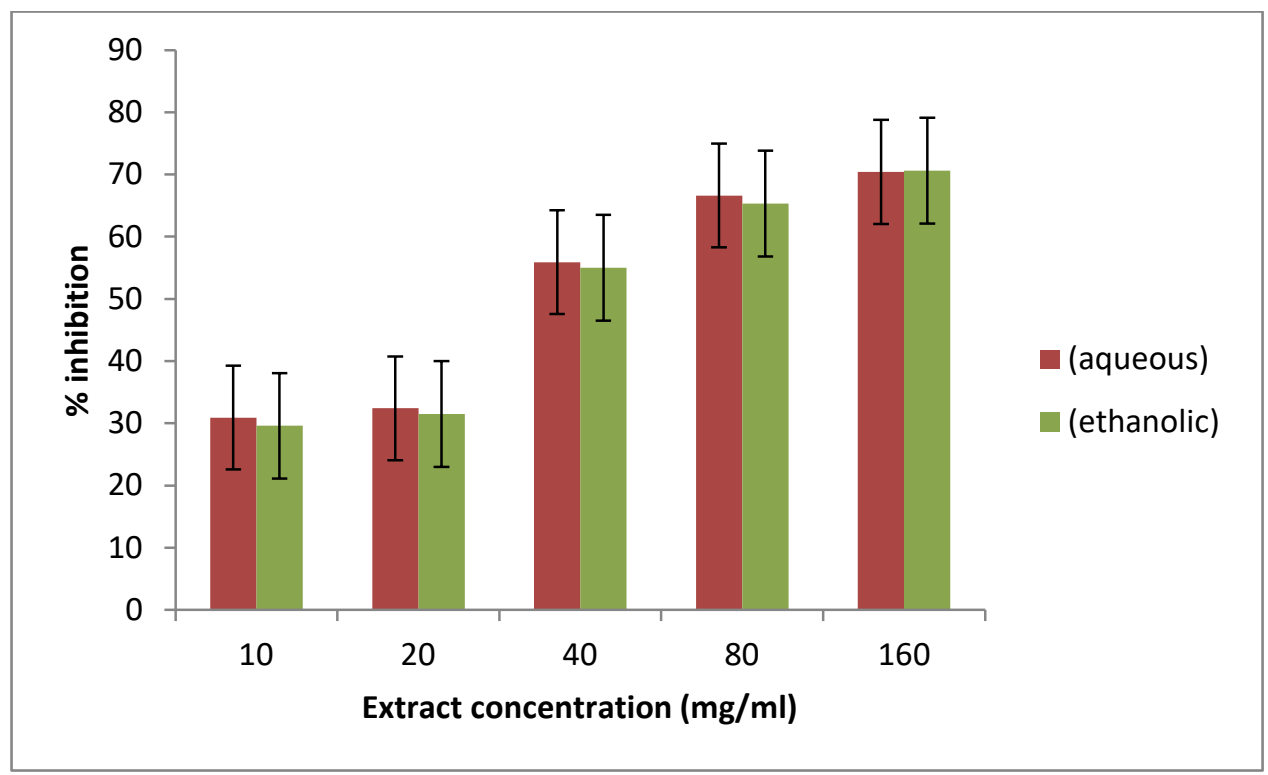

Figure 3: Inhibitory effect of Solanum indicum against $\mathrm{Pb}^{2+}$-induced lipid peroxidation in rat liver

\section{CONCLUSION}

Solanum indicum leaf extract was able to protect the rat liver against lead acetate induced hepatotoxicity signified by biomarker enzymes hyperactivities in group B animals which were restored in group C rats fed with the extract. Besides, the extract was able to protect the liver tissue against $\mathrm{Pb}^{2+}$-induced lipid peroxidation due to its inherent antioxidant properties. This further supports the hypothesis that cellular redox status could be significantly reversed with the use of plants containing flavonoids and phenolic antioxidant compounds.

\section{REFERENCES}

Belle, N.A.V., Dalmolin, G.D., Fanini, G., Rubim, M.A., Rocha, J.B.T. (2004). Effects of polyamines on proxidant-induced lipid peroxidation. Brain Res. 1008: 245-251.

Escribano, A., Revilla, M., Hernandez, E.R., Seco, C., Gonzalez-Riola, J., Villa, L.F., Rico, H. (1997). Effect of lead on bone development and growth; histomorphometric study. Calcif. Tissue Int. 60: 200-203.

Enghehardt, H.J. (1970). Determination of kidney alkaline phosphate activity. Journals of Enzymology, 91: 571-577.

Lorke, T.M.(1983). Assessment of metal concentration and lethal dose practices in laboratory animals. Toxicol. 115: 788-791.

Minotti, G. and Aust, K. (1987). Investigation into mechanism of citrate Fe2+-dependent lipid peroxidation. Journal of Free Radicals Biol. \& Med. Vol. 3: 379-387. 
Reitman, S., and Frankel, S., (1957)., Schmidt S.H. and Schmidt, G., (1963). A calorimetric method for the determination of serum glutamic oxaloacetic and glutamic pyruvic transaminase. Am. J. Clin. Pathol. 28: 56-63.

Roja, G. and Rao, P.S. (2000). Anticancer compounds from tissue cultures of medicinal plants; global importance of medicinal plant resources. J. Herbs. Med. Plants. 7: 71-102. 